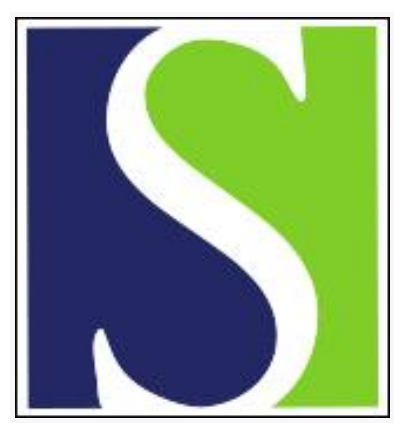

Scand J Work Environ Health 1991;17(4):255-262

https://doi.org/10.5271/sjweh.1705

Issue date: Aug 1991

Manganese exposure in steel smelters a health hazard to the nervous system.

by Wennberg A, Iregren A, Struwe G, Cizinsky G, Hagman M, Johansson L

Affiliation: Department of Neuromedicine, National Institute of Occupational Health, Solna, Sweden.

This article in PubMed: www.ncbi.nlm.nih.gov/pubmed/1925437

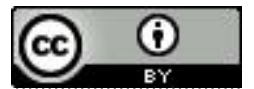




\title{
Manganese exposure in steel smelters a health hazard to the nervous system
}

\author{
by Arne Wennberg, MD, ${ }^{1}$ Anders Iregren, $\mathrm{PhD},{ }^{2}$ Göran Struwe, MD, ${ }^{3}$ \\ Gabriel Cizinsky, MD, ${ }^{3}$ Maud Hagman, ${ }^{1}$ Lotta Johansson ${ }^{1}$
}

\begin{abstract}
WENNBERG A, IREGREN A, STRUWE G, CIZINSKY G, HAGMAN M, JOHANSSON L. Manganese exposure in steel smelters a health hazard to the nervous system. Scand J Work Environ Health 1991; $17: 255-62$. In a study of the effects of low-level exposure to manganese $\left(0.19-1.39 \mathrm{mg} / \mathrm{m}^{3}\right.$ for 1 45 years) 30 men (aged 20-64 years) from two steel smelting works and 60 unexposed referents (aged 22 - 65 years) were examined with the use of a general health inquiry, electroencephalography, event-related auditory evoked potentials, brain-stem auditory evoked potentials, diadochokinesometry, simple and complex reaction time, finger tapping, digit span, mental arithmetic, vocabulary, a coding task, manual dexterity, symptoms, and mood scales, the diagnostic interview scheme, a dynamic rating scale for neurasthenic syndrome, and a comprehensive psychopathological rating scale. No group differences were found in the electroencephalography or the psychiatric examinations. However, there were increased frequencies of some symptoms, the diadochokinesis was slower, the P-300 latency and reaction time were increased, and finger-tapping and digit-span performance were impaired in the exposed group. These effects were interpreted as early (subclinical) signs of disturbances of the same type as parkinsonism.
\end{abstract}

Key terms: manganism, neurophysiology, parkinsonism, psychiatry, psychological performance, smelting works, steel industry.

Manganese has a toxic effect on the central nervous system (1). At high exposure levels there are two types of effects. In the acute phase psychiatric symptoms dominate ("manganese madness") with hallucinations, emotional lability, and compulsive and aberrant behavior. Later, neurological symptoms with muscular weakness, impaired speech, headache, clumsiness, tremor, mild rigidity, and hypokinetic (masklike) facial expressions appear. These symptoms are similar to those seen in Parkinson's disease, and they are typical of chronic manganese poisoning. Microscopic examination of brains from subjects poisoned by manganese has revealed lesions in the extrapyramidal structures (substantia nigra, globus pallidus, subthalamic nucleus, caudate nucleus, and putamen) similar to those found in Parkinson's disease.

Manganism was first described in 1837 for manganese miners (2) and later, in 1907, for workers who had pulverized pyrolusite (3). There are also later case reports (eg, miners in Japan, Chile, Morocco, Cuba, India, Mexico, the Soviet Union, and the United States) (4). In all these cases, the exposure levels were

' Department of Neuromedicine, National Institute of Occupational Health, Solna, Sweden.

2 Department of Psychophysiology, National Institute of Occupational Health, Solna, Sweden.

${ }^{3}$ Department of Psychiatry, Huddinge University Hospital, Huddinge, Sweden.

Reprint requests to: Dr A Wennberg, Department of Neuromedicine, National Institute of Occupational Health, S-171 84 Solna, Sweden. rather high. In a report on 72 Chilean miners (5) exposed to manganese levels of $62.5-250 \mathrm{mg} / \mathrm{m}^{3}$, signs of manganism were found in 12 subjects $(16.5 \%)$. Among 370 miners exposed to $0.5-46 \mathrm{mg} / \mathrm{m}^{3}$, manganism was found in 15 subjects $(4 \%)(6)$, and among 100 subjects exposed to $0.6-8.6 \mathrm{mg} / \mathrm{m}^{3}$ slight neurological symptoms were present in 40 subjects $(40 \%)$ (7). In several reports from the Soviet Union (8-10), the exposure levels were much lower, $0.45-1.2 \mathrm{mg} /$ $\mathrm{m}^{3}$. Many of the exposed subjects exhibited neurological symptoms, but no description was given of the symptoms and the manner of their verification. Effects from low-level exposure to manganese $\left(\approx 1 \mathrm{mg} / \mathrm{m}^{3}\right)$, such as prolonged reaction time, decreased memory capacity, and increased hand tremor, have recently been reported (11). However, the critical level for effects on the central nervous system is not known. The present study was thus performed to investigate possible effects on the central nervous system from exposure to very low levels of manganese among active and essentially asymptomatic workers.

\section{Subjects and methods}

\section{Examined groups}

The exposed group was recruited from two steel smelting works with manganese exposure; it included $30 \mathrm{men}$ aged 19.7-63.7 (mean 46.4) years with a minimum of one year of occupational exposure to manganese (ie, period of employment in present work). 
A reference group of 60 unexposed, age-matched men, aged 22.2-64.7 (mean 44.8) years, was recruited from two adjacent workplaces (a steel rolling mill and an engineering plant) with approximately the same level of physical demand at work as the exposed subjects. One exposed and two unexposed workers refused to participate and were replaced by others.

The exposure to manganese was measured as the mean values of total dust during $8 \mathrm{~h}$. These values varied between different types of work (minimum $0.03 \mathrm{mg} / \mathrm{m}^{3}$ and maximum $1.62 \mathrm{mg} / \mathrm{m}^{3}$ ). For all types of work, the mean values were $0.18 \mathrm{mg} / \mathrm{m}^{3}$ at one smelter and $0.41 \mathrm{mg} / \mathrm{m}^{3}$ at the other. Available data from earlier exposure measurements at the two smelters indicated essentially no changes in the levels of exposure for the past 17 and 18 years, respectively. Based on some actual measurements during the 1970s, the proportion of respirable manganese dust was estimated for each individual. These proportions varied from 20 to $80 \%$.

\section{Data collection}

Each subject was examined during $1 \mathrm{~d}$, beginning with a general health check (questionnaire) during $1 \mathrm{~h}$ and followed by three other types of examination, $2 \mathrm{~h}$ each (neurophysiology, psychology and psychiatry in an order balanced over the exposure groups). The health inventory contained 110 yes/no questions, which, among other things, covered exposure to organic solvents, smoking habits, and previous and present diseases and symptoms.

\section{Neurophysiological examinations}

Electroencephalography. Electroencephalography was performed according to clinical practice on paper with a 16-channel electroencephalograph (Siemens-Elema).

Event-related auditory evoked potential. The eventrelated auditory evoked potential (P-300) examination (12) was performed in a quiet room with the subject semireclined in a comfortable chair. Stimulation through headphones consisted of 50 -ms beeps with a frequency of $1000 \mathrm{~Hz}$ ("repetitive") or $2000 \mathrm{~Hz}$ ("randomized"). The interval between beeps was $2 \mathrm{~s}$, and $25 \%$ of the beeps were of the randomized type. The subjects were instructed to count the number of randomized beeps and keep the accumulated sum in mind during the $17-\min$ examination. Latency to the P-300 peak was measured.

Brain-stem auditory evoked potential. Stimuli for the brain-stem auditory evoked potential consisted of brief $(0.05 \mathrm{~ms})$ clicks through one headphone with a frequency of 10 clicks/s. The response was recorded bipolarly with electrode positions at the vertex and behind the ipsilateral ear (mastoid process). Latencies to peaks I, II, and V (according to clinical standard) were measured, along with differences I-III, III $-\mathrm{V}$, and $\mathrm{I}-\mathrm{V}$.

Diadochokinesometry. Diadochokinesis (ie, the ability to perform rapidly alternating movements with one limb, such as supination/pronation of the forearm) makes high demands on the coordination of activity in different muscles or muscle groups. This coordination is produced by the extrapyramidal nervous system, the function of which is impaired in Parkinson's disease or parkinsonism. A test of diadochokinesis would therefore be suitable for demonstrating early (subclinical) signs of parkinsonism. Alternating wrist movements has previously been used as a test of pharmacological treatment of Parkinson's disease (Lindblom, unpublished report 1989). The recording equipment was the same as that used by Lindblom (a rotatable handle, the movements of which were recorded by a pen recorder). The subjects were told to turn the handle as fast as possible so that the end points corresponded to an almost maximal supination and pronation, respectively, during $30 \mathrm{~s}$. Both hands were examined. Three periods of 10 full turns (cycles) were used from each series to calculate the mean values of frequency (number of full turns per second) and amplitude. Regularity in frequency and amplitude was used as a check for adequate performance. Otherwise there was no way of checking the maximal volition.

\section{Psychological examinations}

The psychological test battery comprised 14 different tasks, among them eight tests and four rating scales from the Swedish Performance Evaluation System (SPES), a computer-administered test battery (13). To supplement these computerized tasks, two manual tests from a traditional test battery (14), one for hand dexterity and the other for finger dexterity, were used. The following tests and scales were administered during the 2-h test session in the order presented.

Self-rating of mood (recently). The self-rating scale consisted of 12 mood descriptive adjectives, coupled to a six-point category scale. The subject was asked to describe his mood during an unspecified recent period by checking the appropriate category. The scores were computed for a stress and an activity dimension.

Acute symptoms. The scale for acute symptoms contained 17 items regarding symptoms of local irritation and symptoms from the central nervous system. The present intensity of each symptom was rated on a fourpoint scale.

Simple reaction time. The simple reaction-time measurement was a sustained attention task lasting for 
6 min and measuring the response speed to an easily discriminated but temporally uncertain stimulus. Performance level was evaluated as the mean response latency in milliseconds for 80 stimuli, and the variability was evaluated as the standard deviation of the individual distribution of latencies.

Finger-tapping speed. The test for finger-tapping speed measured the maximum speed of repetitive finger movement. Performance was evaluated as the mean number of taps for each index finger (dominant/nondominant hand) from two 10 -s trials.

Color word vigilance. A complex reaction-time task which required responses only to a minority of the signals was used for the determination of color word vigilance. The stimulus was a word for a color in Swedish (red, yellow, white, or blue) with the text written in any one of the colors. The task was to press a key as quickly as possible when there was congruency between the color of the text and the meaning of the word. Performance was evaluated as the mean latency for 48 critical signals in 240 trials during $8 \mathrm{~min}$.

Hand dexterity. In the test for hand dexterity the task was to move cylindrical wooden pegs from one board to the corresponding position on another with the use of the dominant hand. The performance measure was the total number of pegs moved during two 40 -s trials.

Digit span. In this traditional test of short-term memory capacity, digit span, series of digits were presented on the computer screen, and the task was to reproduce the series on the keyboard. Memory capacity was estimated from the performance on a minimum of 12 series of digits.

Finger dexterity. In this test of finger dexterity the task was to move small needles from one location to another using a pair of tweezers. The performance measure was the total number of needles correctly placed during $90 \mathrm{~s}$.

Finger-tapping endurance. This test of finger-tapping endurance measured the number of taps performed with the index finger of the dominant hand during one 60-s trial.

Self-rating of mood (at present). The same scale as for recent mood was used, but the subject was asked to evaluate his mood state during the last $10 \mathrm{~min}$. One score was computed for the stress dimension and one for the activity dimension.
Long-term symptoms. Long-term symptoms were determined from a questionnaire comprising 38 items concerning, for example, vegetative symptoms, concentration deficits, fatigue, tiredness, dizziness, and symptoms of peripheral neuropathy. The subject was asked to rate the frequency of occurrence of each symptom during the last six months on a four-point scale.

Additions. The additions test measured the speed of performance of simple arithmetic operations. An addition task comprising three horizontally placed digits was briefly presented, and the subject was asked to perform the addition quickly and enter the sum on the keyboard. The performance measure evaluated was the mean response latency from 40 trials.

Symbol digit. Symbol digit is a revised version of a traditional test of perceptual speed, using a coding task presented on a screen. The responses were entered on the keyboard, and performance was evaluated as the mean response time from 54 stimuli.

Vocabulary. A traditional test of verbal understanding, comprising 45 stimuli, was used for vocabulary. The task was to indicate, among five alternatives, the correct synonym of a key word. The performance measure was the number of correct solutions.

\section{Psychiatric examinations}

Diagnostic Interview Schedule. The Diagnostic Interview Schedule (DIS) is a structured interview designed for screening for psychiatric symptoms, including alcohol and drug abuse, as well as axis I-diagnoses according to the criteria of the diagnostical statistical manual of psychiatric diagnoses III (DSM III) (15). It was used to investigate the presence of psychiatric symptoms in the examined groups. Seven out of the 43 sections were omitted in order to save time, as these seven sections (posttraumatic stress syndrome, anorexia nervosa, bulimia, substance abuse and dependence, transsexualism, pathological gambling, and organic brain syndrome) were considered to be of less interest in the context of our study. The interview was executed by a specialist in general psychiatry, who was trained especially in this technique.

Dynamic Rating Scale for Neurasthenic Syndrome. The Dynamic Rating Scale for Neurasthenic Syndrome (DNS) is a semistructured rating scale comprising 19 items designed with the purpose of detecting and quantifying early symptoms indicating organic brain damage (16). The scale not only rates the severity of symptoms, but also evaluates their clinical relevance in relation to existing psychosocial stressors. Each item is 
therefore made up by one situational (S) and one response $(R)$ scale, each graded into five steps. The steps of the $S$ and $R$ scales are meant to correspond to each other: R-1 to $S-1, R-2$ to $S-2$, and so on. For example, if someone is rated as 1 on the S scale but 4 on the $\mathrm{R}$ scale for the item fatigability, there is accordingly a difference of 3 between the $R$ and $S$ scales, and this result indicates a greater degree of fatigability than expected in this situation. The difference between the $\mathrm{R}$ and $\mathrm{S}$ scales is hence supposed to be a measure of the general inclination to develop stress-related psychiatric symptoms, as is the case, for example, with organic brain syndrome.

Comprehensive Psychopathological Rating Scale. The Comprehensive Psychopathological Rating Scale (CPRS) is a semistructured rating scale designed to quantify 66 psychopathological symptoms (17). It comprises a total of 64 items divided into reported and observed items, and a global rating of the degree of illness, as well as a rating of the reliability of the completed interview. The scale could either be used as a whole or in part. In the evaluation of the present psychiatric state of the examined groups, the items for the observed symptoms, severity of illness (clinical global impression), and reliability of the interview were used.

\section{Statistical methods}

Psychological data. Two-way analyses of variance were performed on the variables from the psychological investigation, exposure group and geographic location being used as the two sources of variation. These analyses revealed differences between the exposure groups on a number of tests, among them the vocabulary test. A group difference on the verbal test is not likely to be an effect of exposure, but may rather be seen as an indication that the groups were not comparable with respect to general cognitive abilities. Thus the difference between the investigated groups on the vocabulary test had to be controlled for in the further analyses of the results.

Such control was achieved in two different ways. One method was to perform a secondary matching, in which the score on the verbal test was included as an additional matching criterion. By this new matching the reference group used for the comparisons of the results on psychological variables was reduced to 30 workers. Following this secondary matching, the analyses of variance were repeated. As a second method, a series of analyses of covariance were performed on the original groups, the score on the verbal test being used as the covariate.

In the testing for possible dose-effect relationships, correlations were computed between the effect measures and the present level of manganese exposure at the time of the study, the number of years of employment in manganese-exposed work, and the accumu- lated dose over the years of employment. These calculations were performed both on measures based on the total amount of manganese dust and the respirable fraction of manganese. Analyses of multiple regression were also performed in which the relationships between the exposure measures and the effects were studied after control for age and vocabulary score.

Other data. For comparisons between the exposed and reference groups, the following methods were used: (i) for the results of the health inquiry (yes/no questions) and psychiatric data the frequencies were calculated for the parameters and tested with Fisher's exact test, two-sided; (ii) continuous variables were analyzed by two-way analyses of variance for the estimation of group differences with respect to exposure and geographic area.

\section{Results}

The subjects in the reference group were more exposed to organic solvents than the exposed group. There were no differences between the groups concerning smoking habits or previous/present diseases.

\section{Reported symptoms}

For two single symptoms, namely, reduced libido and increased tiredness, there was a significantly higher frequency in the exposed group as compared with the group of unexposed workers. For groups of symptoms, like respiratory or airway problems, neurological problems, and symptoms of asthenia, there were consistent, but not significant, shifts $(0.05<\mathrm{P}<0.10)$ towards increased frequencies in the exposed group.

\section{Neurophysiological examinations}

Electroencephalography. The electroencephalography was outside normal limits for $23 \%$ of the exposed men and $15 \%$ of the referents. These figures were somewhat higher than expected, but the difference between the groups was not significant. The abnormal findings were a general increase in the amount of slow waves with or without slight asymmetry. There were no focal abnormalities.

Event-related auditory evoked potential. The P-300 latencies were longer in the exposed group as compared with the reference group. However the differences between the groups were not statistically significant. The individual values are plotted in figure 1.

Brain-stem auditory evoked potential. There was a tendency towards an increased latency for some of the components of the brain-stem auditory evoked poten- 
tial in the exposed group when they were compared with those of the referents, but there were no statistically significant differences demonstrated between the exposure groups.

Diadochokinesometry. The exposed workers showed a lower frequency than the referents (dominant hand 2.67 and $2.93 \mathrm{~Hz}$, respectively, and nondominant hand 2.44 and $2.70 \mathrm{~Hz}$, respectively). However, these differences were not statistically significant $(\mathrm{P}=0.12$ and 0.08 , respectively).

\section{Psychological examinations}

Performance data for the exposed workers and the reference groups, as well as the significance levels for the differences between these groups, are presented in table 1 . The analyses of variance revealed essentially no differences due to geographic area. However, a slight difference, favoring the workers in the southernmost region, was found in the finger tapping endurance test. There were no interactions between exposure and geographic location.

The exposed workers exhibited inferior performance, as compared with that of the secondarily matched reference group, on several of the tasks according to the second series of analyses of variance. Differences were found on tests of simple reaction time, digit span, finger tapping, and additions.

The results from these analyses were largely in accordance with those of the preliminary analyses using the original reference group, and they are presented in table 1. As can be seen from the table, the only group differences to disappear after the secondary matching were those on the verbal test and the test of numerical ability. The magnitude of the effects on the tapping tests and the digit span tests was, on the whole, unaffected by the secondary matching, but the reduced number of subjects following the secondary matching did of course affect the level of significance. Thus some of the differences found originally did not reach statistical significance after the secondary matching.

The results from the analyses of covariance also indicated that most of the differences between the exposed and the reference group were not related to verbal ability. Apart from the difference in the verbal test, only that in the additions test disappeared with these analyses of covariance.

In the analyses of dose-effect relationships, the effect measures were not related to the number of years employed in manganese-exposed work. Nor were there any significant correlations when exposure measures were used, including the total level of manganese dust. However, when the exposure measures used included the estimated level of respirable manganese dust, significant correlations ( $P<0.05$, one-tailed test) were found for three of the eight variables differing between the exposed and the reference group in the neuropsychological examination (simple reaction-time variability, $r=0.31$; digit span, $r=-0.34$; mood recently, activity, $r=-0.48$ ). Thus, after control in the analyses of multiple regression for the effects of age and scores on the vocabulary test, the calculated dose of respirable manganese dust still explained part of the variance in variability on the simple reaction-time test, maximal span length on the digit span test, and the activity score in the mood scale (simple reaction-time variability, $\mathrm{R}=0.47,9 \%$; digit span, $\mathrm{R}=0.62,2 \%$; mood recently, activity, $\mathrm{R}=0.59,9 \%$ ).

\section{Psychiatric examination}

Diagnostic Interview Schedule. With the Diagnostic Interview Schedule the following six psychiatric diagnoses

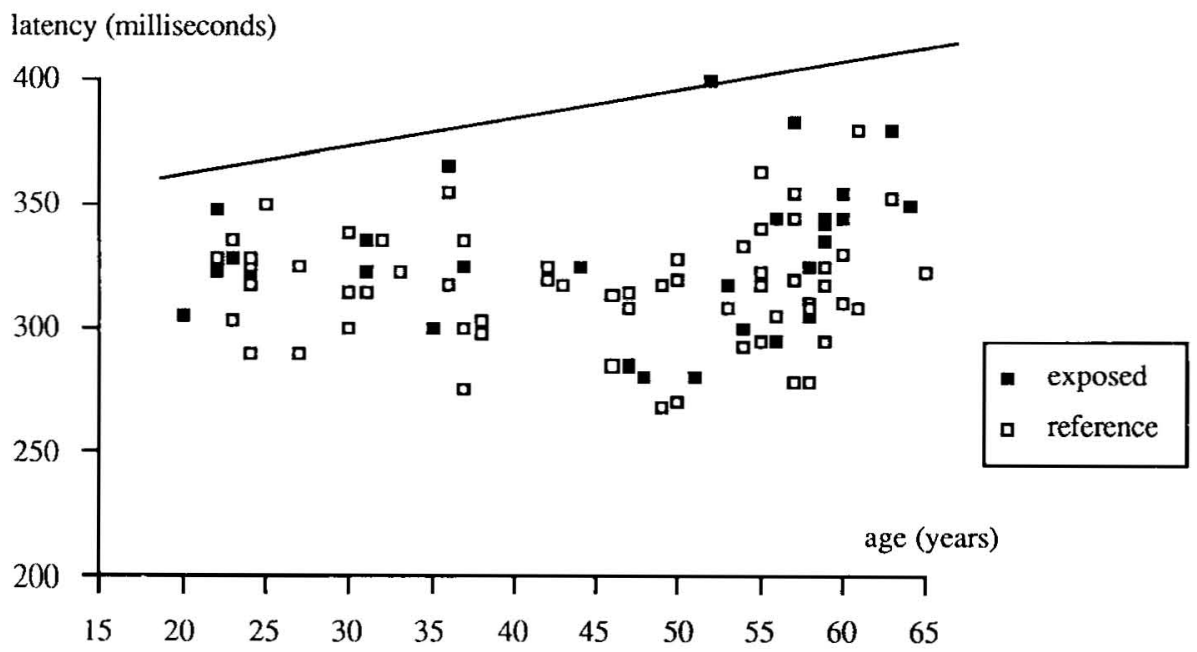

Figure 1. P-300 latencies of the individual subjects. The oblique line indicates the upper normal limit (ie, two standard deviations above the mean value in a normal population) (18). 
Table 1. Mean values of the different performance and subjective rating variables for the exposed group, the original reference group, and the secondarily matched reference group. The significance level for the differences between the exposed and reference groups is also presented. (NS = not significant)

\begin{tabular}{|c|c|c|c|c|c|}
\hline \multirow{2}{*}{ Variable } & \multicolumn{2}{|c|}{ Original groups ${ }^{a}$} & \multirow{2}{*}{$\begin{array}{l}\text { Level of } \\
\text { signifi- } \\
\text { cance }\end{array}$} & \multirow{2}{*}{$\begin{array}{l}\text { Secondarily } \\
\text { matched } \\
\text { reference }^{\mathrm{a}}\end{array}$} & \multirow{2}{*}{$\begin{array}{l}\text { Level of } \\
\text { signifi- } \\
\text { cance }\end{array}$} \\
\hline & Exposed & Reference & & & \\
\hline \multicolumn{6}{|l|}{ Mood recently } \\
\hline $\begin{array}{l}\text { Activity } \\
\text { Stress }\end{array}$ & $\begin{array}{l}17.8 \\
19.5\end{array}$ & $\begin{array}{l}19.5 \\
20.3\end{array}$ & $\begin{array}{r}<0.05 \\
\text { NS }\end{array}$ & $\begin{array}{l}19.8 \\
19.4\end{array}$ & $\begin{array}{r}<0.05 \\
\text { NS }\end{array}$ \\
\hline Acute symptoms $(\mathrm{N})$ & 3.1 & 2.9 & NS & 2.3 & NS \\
\hline \multicolumn{6}{|l|}{ Simple reaction time } \\
\hline $\begin{array}{l}\text { Level } \\
\text { Variability }\end{array}$ & $\begin{array}{r}236 \\
47.9\end{array}$ & $\begin{array}{r}222 \\
42.7\end{array}$ & $\begin{array}{r}<0.05 \\
\text { NS }\end{array}$ & $\begin{array}{r}214 \\
37.7\end{array}$ & $\begin{array}{l}<0.001 \\
<0.05\end{array}$ \\
\hline \multicolumn{6}{|l|}{ Tapping speed } \\
\hline $\begin{array}{l}\text { Dominant } \\
\text { Nondominant }\end{array}$ & $\begin{array}{l}59.9 \\
54.0\end{array}$ & $\begin{array}{l}64.5 \\
58.8\end{array}$ & $\begin{array}{l}<0.01 \\
<0.01\end{array}$ & $\begin{array}{l}64.0 \\
57.1\end{array}$ & $\begin{array}{r}<0.05 \\
\text { NS }\end{array}$ \\
\hline Color words, reaction time & 530 & 538 & NS & 530 & NS \\
\hline Hand dexterity & 76.2 & 79.1 & NS & 78.3 & NS \\
\hline Digit span & 6.4 & 7.0 & $<0.05$ & 6.9 & NS \\
\hline Finger dexterity & 26.0 & 26.8 & NS & 26.4 & NS \\
\hline Tapping endurance & 280 & 309 & $<0.05$ & 304 & NS \\
\hline \multicolumn{6}{|l|}{ Mood at present } \\
\hline $\begin{array}{l}\text { Activity } \\
\text { Stress }\end{array}$ & $\begin{array}{l}19.5 \\
19.8\end{array}$ & $\begin{array}{l}21.1 \\
20.7\end{array}$ & $\begin{array}{r}<0.05 \\
\text { NS }\end{array}$ & $\begin{array}{l}21.1 \\
21.0\end{array}$ & $\begin{array}{l}\text { NS } \\
\text { NS }\end{array}$ \\
\hline Symptoms $(\mathrm{N})$ during the last 6 months & 16.5 & 12.8 & $<0.05$ & 12.3 & $<0.05$ \\
\hline Additions, reaction time & 4.8 & 4.1 & $<0.05$ & 4.4 & NS \\
\hline Symbol digit & 3.6 & 3.3 & NS & 3.5 & NS \\
\hline Vocabulary & 15.3 & 21.7 & $<0.01$ & 17.3 & NS \\
\hline
\end{tabular}

a Mean age: exposed group 46.4 years, original reference group 44.8 years, secondarily matched reference group 46.1 ; mean number of years of employment: exposed group 9.9 years, original reference group 11.8 years, secondarily matched reference group 13.4 years.

were found in the examined groups: alcohol abuse (continuous and in remission), nicotine dependence (continuous and in remission), general anxiety disorder, and simple phobias. The two later diagnoses were established only in the reference group, but the differences were not significant.

Dynamic Rating Scale for Neurasthenic Syndrome. The Dynamic Rating Scale for Neurasthenic Syndrome did not show any significantly raised level of stressors in the exposed group, as compared with the referents. Neither was there any difference in response between the exposed and the reference groups, either for the total score or for the individual items.

The inclination to develop stress-related psychiatric symptoms (as determined by the difference between the $\mathrm{R}$ and $\mathrm{S}$ scales) did not differ significantly between the groups, neither for total score nor for any individual item.

Comprehensive Psychopathological Rating Scale. The Comprehensive Psychopathological Rating Scale did not show any significant differences between the groups for the observed items, neither generally nor for any individual item. Neither was any difference observed for the rated "severity of illness" (CGI).

\section{Discussion}

In the present investigation effects attributable to lowdose manganese exposure were found for reported symptoms, neurophysiological measures, and psychological performance measures.

Symptom frequencies were studied by the use of a paper-and-pencil questionnaire, as well as by two computer-administered symptom scales. We found an overrepresentation in the exposed group as compared with the reference group for symptoms of fatigue and decreased libido and tendencies towards an increase in symptoms of the airways, peripheral neuropathy, and asthenic symptoms. According to the WHO criteria document on manganese (19), this general symptomatology is well in agreement with results from several previous studies.

The neurophysiological findings in the present study (ie, an increased P-300 latency and a tendency towards impaired diadochokinesis) are compatible with a defect in extrapyramidal (central motor) functions and effects on efferent (sensory) signal processing. Parkinsonism is characterized by such an influence on extrapyramidal functions, and an increased P-300 latency has been demonstrated also for patients with parkinsonism or Parkinson's disease $(20,21)$. Furthermore, an increased latency of the brain-stem auditory evoked potential has also been reported in cases of parkin- 
sonism (22). A tendency towards such an increase was also found in the present study. Our findings are thus similar to the parkinsonism-like signs seen in manganism.

The findings in the psychological part of this study were also in accordance with those in previous investigations of exposed workers and clinical case reports on the neurotoxic effects from manganese exposure (19). The manganese-exposed workers in our study performed less well than the unexposed reference group on tests measuring reaction time, motor speed, and short-term memory. These effects on psychological test performance are clearly consistent with those recently reported in a Belgian study (11) of effects from low-dose manganese exposure among asymptomatic workers.

The negative results from the psychiatric part of the present investigation may at first glance seem somewhat surprising, since the psychiatric symptoms, those of the so-called "manganese madness," are an important part of the classic picture of acute manganese intoxication. This symptomatology has, however, been found in acutely intoxicated cases exposed to very high concentrations of manganese dust in the air. A comparison between these cases and the essentially asymptomatic exposed group in the present investigation is probably not justifiable.

Although there was a general consistency between the slight effects of low-dose manganese exposure found in this study and previously reported effects on subjects exposed to higher levels, only weak dose-effect relationships were found within the presently studied exposed group. Such relationships were found only for three variables in the psychological examination, namely, variability in a reaction-time test, maximal performance in a memory test, and activity ratings on a mood scale. These relationships do, however, seem very stable since they appear in the analyses of multiple regression even after control for age and education. Still, in a sample of this small size, a few individuals with rather extreme values contribute considerably to the correlations found. The dose-effect relationships found in this study should thus be regarded as tentative, and further studies may eventually confirm the usefulness of the respirable fraction of manganese dust in the evaluation of dose-effect relationships among manganese-exposed workers.

To summarize, our results show that long-term exposure to very low levels of manganese in the air may interfere with the normal functioning of the central nervous system. These effects are interpreted as a preclinical stage of the full-blown manganism previously reported from high-level occupational manganese exposures.

In conclusion, our results indicate that present hygienic limits for manganese exposure, in Sweden 2.5 $\mathrm{mg} / \mathrm{m}^{3}$ and in most other countries $5 \mathrm{mg} / \mathrm{m}^{3}$, are not sufficient to protect workers from negative effects on the central nervous system. However, further research is needed to establish the long-term health implications of the effects found in this investigation.

\section{Acknowledgments}

This work was sponsored by the Swedish Work Environment Fund (88-0293). We also gratefully acknowledge the help provided by Mr A Olsson, Svedalahälsan, who performed the exposure measurements.

\section{References}

1. Politis MJ, Schaumburg HH, Spencer PS. Neurotoxicity of selected chemicals. In: Spencer PS, Schaumburg $\mathrm{HH}$, ed. Experimental and clinical neurotoxicology. Baltimore, MD: Williams \& Wilkins, 1980:618-9.

2. Couper J. On the effect of black oxide of manganese when inhaled into the lungs. Br Ann Med Pharm Vital Stat Gen Sci 1837;1:41-2.

3. von Jaksch $R$. Über Mangantoxikosen und Manganophobie. Münsch Med Wochenschr 1907;54(20): 970-2.

4. Meña I. Manganese poisoning. In: Vinken PJ, Bruyn $\mathrm{GW}$, ed. Handbook of clinical neurology, intoxications of the nervous system; vol 36 (Part-I). Amsterdam: North Holland Publishing Company, 1979:217.

5. Ansola J, Viberall E, Escudero E. La intoxication por manganeso en Chile (Estudio sobre 64 casas): 1. a communication: factores ambientales y etrupatogenia. Rev Med Chile 1944;72:222-9.

6. Schuler $\mathbf{P}$, Oyanguren $\mathbf{H}$, Maturana V, et al. Manganese poisoning: environmental and medical study at a Chilean mine. Ind Med Surg 1957;26:167-73.

7. Suzuki Y, Nishiama K, Suzuki Y. The effects of chronic manganese exposure on ferromanganese workers: part 2 [in Japanese]. Shikoku Acta Med 1973;29(6):433-8. (English summary.)

8. Gordnova NB. Clinical picture and cause of manganese poisoning at simultaneous exposure to aerosols of manganese oxides formed by condensation, local vibrations and physical strain [in Russian]. Sverdlovsk: Institut Gigieny Truda i Professionalnyh Zabolevanij, 1967. Cited in: WHO Study Group. Recommended healthbased limits in occupational exposure to heavy metals: report of a WHO study group. Geneva: World Health Organization, 1980. (WHO technical report series; no 647.)

9. Karnauch NG, et al. Air pollution in old and new foundries of ferroalloys [in Russian]. In: Proceedings of a conference on occupational hygiene and prevention of occupational diseases in ferroalloy production [in Russian]. Sverdlovsk: Institut Gigieny Truda i Professionalnyh Zabolevanij 1973:27. Cited in: WHO Study group. Recommended health-based limits in occupational exposure to heavy metals: report of a WHO study group. Geneva: World Health Organization 1980. (WHO technical report series; no 647.)

10. Kovalcuk AA, Brodski BO. Health of the workers in ferroalloys foundries [in Russian]. In: Proceedings of a conference on occupational hygiene and prevention of occupational diseases in ferroalloy production [in Russian]. Sverdlovsk: Institut Gigieny Truda i Professionalnyh Zabolevanij 1973:78. Cited in: WHO Study group. Recommended health-based limits in occupational exposure to heavy metals: report of a WHO study group. Geneva: World Health Organization 1980. (WHO technical report series; no 647.)

11. Roels H, Lauwerys R, Buchet J-P, et al. Epidemiological survey among workers exposed to manganese: ef- 
fects on lung, central nervous system, and some biological indices. Am J Ind Med 1987;11:307-27.

12. Donchin E. Event-related brain potentials: a tool in the study of information processing. In: Begleiter, ed. Evoked brain potentials and behavior. New York, NY: Plenum Press 1979:13-88.

13. Gamberale $F$, Iregren $A$, Kjellberg A. SPES: assessing the effects of the work environment on man with computerized performance testing. In: Karwowski W, Genaidy AM, Asfour SS, ed. Computer-aided ergonomics: a researcher's guide. London: Taylor \& Francis, 1990:381-96.

14. Frömark A, Gamberale F, Sjöberg Å. Ett psykologiskt testbatteri för beteendetoxikologiska undersökningar [A psychological test battery for behaviour toxicological examinations: application of a previously standardized battery]. Stockholm, University of Stockholm, 1979:104. (Information från PTI.)

15. Robins LN, Helzer JE, Croughan JL, Ratcliff $K$. The NIMH diagnostic interview schedule; its history, characteristics and validity. Arch Gen Psychiatry 1981;38: $381-9$.

16. Johnsson-Sundström I. DNS-enny psykiatrisk skattningsskala [DNS, a new psychiatric rating scale]. Arbete människa miljö 1984:3.
17. Åsberg M, Perris C, Schalling D, Sedvall G. The CPRS - development and applications of a psychiatric rating scale. Acta Psychiatr Scand Suppl 1978;271:1-69.

18. Syndulco K, Hansch EC, Cohen SN, et al. Long-latency event-related potentials in normal ageing and dementia. In: Courjon J, Mauguiere F, Revol M, ed. Clinical applications of evoked potentials in neurology. New York, NY: Raven Press, 1982:279-85.

19. World Health Organization (WHO). Manganese. Geneva: WHO, 1981. (WHO environmental health criteria; no 17.)

20. Gil R, Neau JP, Toullat G, Rivasseau-Jonveaux T, Lefèvre JP. Maladie de Parkinson et potentiels évoqués cognitifs. Rev Neurol 1989;145:201-7.

21. Starkstein SE, Esteguy $M$, Berthier ML, Garcia $H$, Leiguarda R. Evoked potentials, reaction time and cognitive performance in on and off phases of Parkinson's disease. J Neurol Neurosurg Psychiatry 1989;52:33840.

22. Tachibana H, Takeda M, Sugita M. Electrophysiological differences between Parkinson's disease and vascular parkinsonism. Jpn J Med 1988;27:261-6.

Received for publication: 18 January 1991 